\title{
RELAÇÕES ÉTNICO-RACIAIS: \\ currículo, avaliação, educação e diversidade
}

\author{
Mário Luiz de Souza ${ }^{1}$ \\ João Paulo Carneiro²
}

\section{RESUMO}

Este artigo propõe discutir na esfera das relações étnico-raciais, currículo, avaliação, educação e diversidade. Diante do desafio proposto dialogamos com autores que compreendem "raça" e racismo na dimensão social e política, ou seja, como categoria analítica indispenásvel na luta para uma educação antirracista (GUIMARÃES, 2009; HALL, 2013; MUNANGA, 2012; SCHWARCZ, 1993; DOMINGUES, 2004; SKIDMORE, 2002; SANTOS, 1997). No campo do currículo travamos um debate no sentido crítico, pós-critico e pós-estruturalista (ARROYO, 2011; APPLE, 2011; HALL, 2014; SILVA, 2010; GIROUX, 2011; MACLAREN, 2011). No âmbito de uma pedagogia da diversidade, a perspectiva da interculturalidade (CANDAU, 2014; MUNANGA, 2014; GOMES, 2010). Uma breve análise de algumas questões de história no caderno de avaliação do SAERJINHO (2013-2014). Possibilitando assim, uma educação democrática na dimensão do respeito à diferença, à equidade e no empoderamento dos grupos inferiorizados no processo histórico.

Palavras-chave: Relações Étnico-Raciais. Currículo. Diversidade.

\section{ETHNIC-RACIAL RELATIONS: curriculum, evaluation, education and diversity}

\begin{abstract}
This article proposes to discuss in the sphere of ethnic-racial relations, curriculum, evaluation, education and diversity. In the face of the challenge proposed, we have a dialogue with authors who understand "race" and racism in the social and political dimension, that is, as an analytical category that is unstoppable in the struggle for antiracist education (GUIMARÃES, 2009; HALL, 2013; MUNANGA, 2012; SCHWARCZ, 1993; DOMINGUES, 2004; SKIDMORE, 2002; SANTOS, 1997). In the field of the curriculum, we have a debate in the critical, post-critical and post-structuralist sense (ARROYO, 2011, APPLE, 2011, HALL, 2014, SILVA, 2010, GIROUX, 2011, MACLAREN, $2011)$. In the context of a pedagogy of diversity, the perspective of interculturality (CANDAU, 2014, MUNANGA, 2014 and GOMES, 2010). A brief analysis of some history

\footnotetext{
1 Doutor em educação (UFF), professor do Programa de Pós-Graduação em Relações maraols@uol.com.br

2 Doutorando em História Social (UERJ). Mestre em Relações Étnico-Raciais, CEFET/RJ. Professor titular do Programa de Pós-Graduação em Cultura Afro-Brasileira e Indígena, Universidade Católica de Petrópolis. Orcid iD: http://orcid.org/0000-0001-9897-0248. E-mail: professorjp@folha.com.br
} Étnico-Raciais do (CEFET/RJ). Orcid iD: http://orcid.org/0000-0002-0150-2366. E-mail:
\end{abstract}


issues in the SAERJINHO evaluation book (2013-2014). This enables a democratic education in the dimension of respect for difference, equity and the empowerment of inferiorized groups in the historical process.

Keywords: Ethnic-Racial. Curriculum. Diversty.

\section{RELACIONES ÉTNICO-RACIALES: currículo, evaluación, de la educación y la} diversidad

\section{RESUMEN}

Este artículo propone discutir en la esfera de las relaciones étnico-raciales, currículo, evaluación, educación y diversidad. En el marco del desafío propuesto dialogamos con autores que comprenden "raza" y racismo en la dimensión social y política, o sea, como categoría analítica, en la lucha por una educación antirracista (GUIMARÃES, 2009; HALL, 2013; MUNANGA, 2012; SCHWARCZ, 1993; Y en el caso de las mujeres. En el campo del currículo se discute en el sentido crítico, post-critico y post-estructuralista (ARROYO, 2011; APPLE, 2011; HALL, 2014; SILVA, 2010; GIROUX, 2011; MACLAREN, 2011). En el ámbito de una pedagogía de la diversidad la perspectiva de la interculturalidad (CANDAU, 2014, MUNANGA, 2014, GOMES, 2010). Un breve análisis de algunos problemas de historia en el librode evaluación de SAERJINHO (2013-2014). Posibilitando así una educación democrática en la dimensión del respeto a la diferencia, la equidad y el empoderamiento de los grupos inferiores en el proceso histórico.

Palabras clave: Relaciones Étnico-Raciales. Currículo. Diversidad.

\section{CONSIDERAÇÕES GERAIS}

Um estranho paradoxo é proposto por Pablo Gentili com referência à instituição escolar. "Ao mesmo tempo em que dela não se espera nada, dela também se espera tudo" (GENTILI, 2008, p.117). É certo que a instituição escolar não consagra-se a grande vilã de "todos" os males sociais, no entanto, o fato é que, a escola pode contribuir para a diminuição de alguns flagelos, sobretudo, na luta antirracista. Não temos como discutir a construção do currículo, das políticas públicas de avaliação, da educação, da diversidade e ignorar a instituição escolar, principalmente, na dimensão da herança iluminista do período moderno, que concebe a instituição escolar como pública, gratuita, laica e, no processo histórico, obrigatória. Por isso, justifica-se a temática como apresentada nesta introdução.

Diante de tamanhos desafios para a instituição escolar concordamos com o autor que entre encantos e desencantos sugere que em tempos de 
desencantamento é preciso construir uma "pedagogia da esperança" (GENTILI, 2008, p.119). A pedagogia da esperança para o pesquisador consiste numa pedagogia da igualdade pela igualdade. Entretanto, nos deparamos com a seguinte questão: como construir uma prática pedagógica igualitária numa teia ou rede de desigualdades sociais, principalmente, se tratando das desigualdades raciais como no caso brasileiro? Para a professora Verena Alberti, tanto o adolescente branco quanto o negro tem muito a ganhar com uma educação habilitada das relações étnico-raciais (ALBERTI, 2013). Portanto, neste artigo trataremos as discussões propostas da seguinte maneira. Em primeiro lugar, vamos discorrer sobre a categoria analítica que nos é cara neste debate, isto é, "raça"3 e racismo. Em segundo, a questão do currículo e suas implicações e relações de poder. Terceiro, o âmbito da avaliação, sobretudo no atravessamento do ensino-aprendizagem e sua "obsessão avaliativa" apontada por alguns pesquisadores. Quarto e último referente às críticas tecidas sobre as possibilidades que apontam construções para uma educação diversa.

Antes de enveredar a respeito do conceito analítico de "raça" e racismo, torna-se de grande importância sinalizar a Lei 10.639/03 introduzida na Educação Básica. O Plano Nacional de Implementação das Diretrizes Curriculares Nacionais para a Educação das Relações Étnico-Raciais e para - Ensino de História e Cultura Afro-Brasileira e Africana traz em sua publicação dois relevantes parágrafos ${ }^{4}$ que apontam sentidos e procedimentos compreendidos neste texto como potência para uma educação atirracista. Feita esta ressalva, nos importa na próxima seção a categoria "raça" e racismo.

\footnotetext{
3 O termo raça utilizado com aspas traz o sentido que diferencia a questão do determinismo biológico utilizada nas teorias racialista do século XIX, do conceito utilizado neste artigo como categoria analítica social, política, discursiva e sociológica de acordo com o suporte teórico discutido.

${ }^{4} \S 1^{\circ} \mathrm{O}$ conteúdo programático a que se refere o caput deste artigo incluirá o estudo da História da África e dos Africanos, a luta dos negros no Brasil, a cultura negra brasileira e o negro na formação da sociedade nacional, resgatando a contribuição do povo negro nas áreas social, econômica e política pertinente à História do Brasil.

$\S 2^{\circ}$ Os conteúdos referentes à História da África e Cultura Afro-Brasileira serão ministrados no âmbito de todo o currículo escolar, em especial nas áreas de Educação Artística e de Literatura e História Brasileira (MEC; SECADI, 2013, P.75).
} 


\section{"Raça" e racismo: uma categoria analítica indispensável}

O debate teórico e conceitual de "raça" e racismo está imbricado e intrínseco. O conceito de "raça", como qualquer outro conceito, não está imune a críticas. Nesse sentido, Guimarães (2012) ressalta as críticas apontadas por Paul Gilroy referente ao conceito, entretanto, o sociólogo destaca o seu posicionamento referente à importância do entedimento de "raça" ser indispenásvel no combate ao racismo no Brasil tanto no quesito analítico quanto no desvelamento da questão de classe, ou seja, para além da classe também racial.

Tomamos o mesmo entendimento aqui tratado e na mesma linha teórica, os demais autores elencados neste debate. Para Hall (2013) raça é uma construção discursiva, um significado flutuante. Raça é um sistema cultural e como sistema cultural é fruto de uma construção e como construção, poder-se-á sofrer processos de desconstrução. Portanto, tratamos o conceito de "raça" não no sentido biológico, pois fica entendido de acordo com Munanga (2012) que, cientificamente estamos diante de uma caducidade do conceito biológico, porém não invalidada na perspectivasociológica, política e social.

Diante da posição teórica dos autores supracitados Munanga (2012) sintetiza da seguinte maneira: "Ser negro é ser excluído" (p.16). Portanto, pouco importa a classe social, pois, as observações contemporâneas a respeito do debate classe e raça, a realidade construída de exclusão para a população de negros é notória, segundo os especialistas aqui tratados. Santos (1997) assevera que a corporalidade, isto é, o corpo negro é um incômodo na esfera social racista. Mesmo que este corpo (sujeito negro) desfrute de certas posições sociais, culturais e econômicas. "[...] Não sou um cidadão integral deste país [...]" (p.135). Uma afirmação dura e pesada, entretanto, uma denúncia no que tange uma pseudo incorporação social do negro no processo histórico brasileiro.

Dito isto, compreende-se que para Munanga (2012), Hall (2013), Guimarães (2012), o conceito de "raça" é uma garantia política para combater o racismo, dito de outra forma, uma categoria analítica 
antirracista. Recorremos também ao dicionário de Cashmore (2000) quanto à palavra racismo com os seus vários sentidos. Em 1960 a palavra foi aplicada no sentido amplo que englobava "[...] práticas, atitudes e crenças; nesse sentido, o racismo denota todo o complexo de fatores que geram a discriminação racial [...] também aqueles fatores que produzem as desvantagens raciais". É descrito também como um complexo histórico, idealizado através da expansão capitalista que engendra um conjunto de ações para tratar a mão de obra negra como um bem, sobretudo, na ideologia da inferioridade, esse complexo histórico denominado de racismo. Seguindo a trajetória dos sentidos pesquisados pelo autor, encontramos também que "[...] A imputação de características negativas reais ou supostas a um determinado grupo é geralmente vista como um traço central do racismo como ideologia. Esta é a base comum dos autores na atualidade" (CASHMORE, 2000, p.458-461).

O filósofo Kwame Appiah destaca diversas teorias que disputam 0 termo racismo e indica que três são fundamentais, a saber, o racialismo (como teoria das raças-racismo), o racismo intrínseco e o extrínseco. O autor em sua teoria sobre o racismo faz duas distinções, ou seja, racismo intrínseco e extrínseco 5 .

Tanto os que são marcados no corpo como os que apresentam diferenças culturais e religiosas, são também caracterizados em termos físicos, embora talvez não tão visível quanto os negros, o referente biológico nunca opera isoladamente, porém, nunca está ausente, ocorrendo de forma mais indireta nos discursos de etnia. "Portanto, o racismo biológico e a discriminação cultural não constituem dois sistemas distintos, mas, dois registros do racismo" (HALL, 2013, p.78).

Não podemos avançar na reflexão sobre o racismo sem antes pensar o que é ser negro. Referindo-se a Hall (2014) que compreende a identidade como "deslizante e flutuante", ou seja, de maneira não essencialista, apresenta o seguinte resumo: "[...] de acordo com alguns teóricos, o

${ }^{5}$ APPIAH, 1997. Sugerimos a leitura dos seguintes capítulos: 33-35 para uma analíse de tais diferenciações. Consultar nas referências.

Revista Exitus, Santarém/PA, Vol. 9, N 5, P. 160 - 189, Edição Especial 2019. 
"sujeito" do lluminismo, visto como tendo uma identidade fixa e estável, foi descentrado, resultando nas identidades abertas, contraditórias, inacabadas, fragmentadas, do sujeito pós-moderno" (HALL, 2014, p.28). O culturalista ainda afirma que "[...] são pensamentos que me impulsionaram a falar [...] do fim da inocência do sujeito negro ou do fim da noção ingênua de um sujeito negro essencial" (HALL, 2013, p.386). Para exemplificar as cadeias de significantes do significado de ser negro, o autor narra às experiências de sua juventude na Jamaica, onde mesmo tendo a pele escura como o da sua classe de pertença, figurava nas camadas médias da sociedade jamaicana e não era identificado como negro, entretanto, na Inglaterra sua identidade desliza, ou seja, passa a ser reconhecido como negro. Essa relação sem fixidez se torna mais evidente na seguinte explanação do autorb. Essas representações, sobretudo, mentais são reproduzidas ou compartilhadas pelas coletividades sociais. Assim, as ideologias representam "[...] quem somos o que fazemos, por que o fazemos como (deveríamos ou não deveríamos) fazê-lo, e para quem o fazemos, ou seja, nossa identidade, ações, objetivos, normas e valores, recursos e interesses sociais". 7 Portanto, não nos interessa traçar uma história das teorias racistas no mundo e no Brasil, mas apontar a sua urgência no sentido de suas interferências nas políticas públicas, sobretudo educacionais no processo histórico.

\footnotetext{
${ }^{6} \mathrm{O}$ sistema caribenho era organizado pelas finas estruturas de classificação dos discursos coloniais de raça, organizadas em uma escala ascendente até o termo máximo "branco" este último sempre fora do alcance, o termo impossível, "ausente", cuja presença-ausência estruturava toda a cadeia. Na luta ferrenha por um lugar e uma posição, que caracteriza as sociedades dependentes, cada grau da escola possui profunda importância. Em contrapartida, o sistema inglês era organizado em torno da dicotomia mais simples, mais apropriada à ordem colonizadora: "branco/não branco". O significado não é um reflexo transparente do mundo da linguagem, mas surge das diferenças entre os termos e categorias, os sistemas de referência, que classificam o mundo e fazem com que ela seja apropriado desta forma pelo pensamento social e o senso comum (HALL, 2013, p.207).

7 VAN DIJK, T. A. Ideologia. Disponível em: www.discursos.org. Acesso em: 01 de maio de 2016.
} 


\section{Currículo: território em disputa e a obsessão avaliativa}

Antes de adentrar na questão do currículo e suas implicações de acordo com o aporte teórico aqui discutido, acredito que seja necessário trilhar de maneira breve no tocante a política pública. Müller e Coelho (2014) resumem as principais características que comporiam as definições e os modelos de política pública para Souza (2006):

- A política pública permite distinguir entre o que o governo pretende fazer e o que, de fato faz;

- A política pública envolve vários atores e níveis de decisão, embora seja materializada através dos governos, e não necessariamente se restringe a participantes formais, já que os informais são também importantes;

- A política pública é abrangente e não se limita a leis e regras;

- A política pública é uma ação intencional, com objetivos a serem alcançados;

- A política pública, embora tenha impactos no curto prazo, é uma política de longo prazo;

- A política pública envolve processos subseqüentes após sua decisão e proposição, ou seja, implica também implementação, execução e avaliação (MÜLLER; COELHO, 2014, p.47 apud SOUZA, 2006, p.38).

Diante do exposto, é possível captar nas conclusões da autora que a prioridade da política pública escrupulosamente está na análise do tipo de problema que necessita ser corrigido pela política pública. "[...] A trajetória seguida e o papel dos indivíduos, grupos e instituições que estão envolvidos na decisão e que serão afetados pela política pública" (SOUZA, 2006, p.40). Compreendemos neste artigo, que a Lei 10.639/03 compõe uma gama de políticas públicas de ação afirmativa que possibilita e pretende recompor as atrocidades históricas que foram cometidas contra a população de negros e negras, causando, por séculos, silenciamentos, invisibilidades e ausências na história brasileira.

Há uma enorme concordância entre os diversos pesquisadores que apontam a importância dos movimentos sociais, principalmente, do movimento negro na construção da Lei 10.639/03. Mesmo diante dos desafios a serem superados, reconhecemos que também há um considerável "[...] avanço da consciência democrática e das demandas por uma sociedade mais justa, pois se insere no âmbito da luta pela educação 
inclusiva, em todos os níveis" (MüLLER; COELHO, 2014, p.49). Na luta antirracista e anti-hegemônica, a legislação abre o espaço para as potencialidades, à valorização da população negra, principalmente, no âmbito educacional, como ampliação no que tange à educação inclusiva, como foi apontado pelas autoras anteriormente. O quesito inclusão é vislumbrado pelas autoras como representações sociais, antes invisíveis nas representações nacionais. Assim dito, o campo de batalha, ou dito de outra maneira o campo de disputa, entra em cena com o seu protagonista, o currículo.

Não existe neutralidade no currículo, assim como, não há neutralidade em nenhum campo científico. Em Apple $(2011)^{8}$ encontramos bons argumentos e justificativas da não neutralidade.

Muitas são as ponderações do autor e de vital importância para a nossa discussão, pois, tenciono tratar a questão do currículo como território em disputa (ARROYO, 2011), como documento de identidade (SILVA, 2011) e como campo de tensões, conflitos, concessões culturais, políticas e econômicas (APPLE, 2011). Diante da consciência das tensões e conflitos, temos a inclusão de um conteúdo que outrora fora negligenciado e invisibilizado, isto é, a Cultura Afro-Brasileira, a Indígena e a História da África. Portanto, a construção identitária da população negra no Brasil "é elaborada de forma individual e socialmente diversa. No caso brasileiro, essa tarefa torna-se ainda mais complexa, pois se realiza na articulação entre classe, gênero e raça no contexto da ambiguidade do racismo brasileiro e da crescente desigualdade social" (GOMES, 2010, p.98). Nesse território em disputa é de suma importância que no âmbito das políticas públicas, sobretudo, o currículo, é necessário o debate da desconstrução eurocêntrica, ou seja, eurocentrismo aqui entendido como construção hegemônica de determinados saberes em detrimento de outros.

\footnotetext{
${ }^{8} \mathrm{~A}$ educação está intimamente ligada à política da cultura. O currículo nunca é apenas um conjunto neutro de conhecimentos, que de algum modo aparece nos textos e nas salas de aula de uma nação. Ele é sempre parte de uma tradição seletiva, resultado da seleção de alguém, da visão de algum grupo acerca do que seja conhecimento legítimo. É produto das tensões, conflitos e concessões culturais, políticas e econômicas que organizam e desorganizam um povo (APPLE, 2011, p 71).
} 
Analogamente, podemos apresentar como Lander (2005) aponta a respeito da força do pensamento hegemônico neoliberal que se constitui em "sua capacidade de apresentar sua própria narrativa histórica, como conhecimento objetivo, científico e universal e sua visão da sociedade moderna, como forma mais avançada - e, no entanto, a mais normal da experiência humana [...]" (LANDER, 2005, p.22). Tamanha desconstrução eurocêntrica encontra voz e força nas obras de inúmeros autores e autoras da América Latina (QUIJANO; CASTRO-GÓMEZ; CORONIL; DUSSEL; ESCOBAR; SEGRERA; MIGNOLO; MORENO; 2005; GOMES, 2010). E no que tange o aspecto da diversidade é compreendido na seguinte dimensão: "Por diversidade, entende-se uma gama de questões como diferença de classe, território, cor/raça, etnia, gênero, deficiência física e mental e de gêneros" (GONÇALVES, 2009, p.91). De forma que, se tratando da diversidade, está intrínseca a questão da pluralidade, do multiculturalismo e da interculturalidade, temas imbricados e caros nesta discussão.

Munanga (2014), discutindo sobre a importância da História do negro e da África no sistema educativo brasileiro, faz coro com os diversos especialistas (dos quais alguns constam citados neste trabalho), quanto à questão do eurocentrismo em nosso currículo e afirma que "além de ser monocultural, não respeita nossa diversidades de gêneros, sexo, religiões, classe sociais, 'raças' e etnias" (MUNANGA, 2014 p.21). Para o antropólogo, o viés monocultural implica uma construção de um Estado-Nação que se embasa em uma "única cultura, isto é, numa única língua, numa única religião, numa única visão de mundo" (Ibid., p. 21). Ainda de acordo com o autor, essa postura está se tornando cada vez mais rara no mundo, pois, se tornou uma questão de agenda para as políticas públicas de vários países sobre a "diversidade cultural e/ou étnico-racial" (Ibid., p.21).

No sentido de uma identidade plural, o Brasil se apresenta como um excelente exemplo, pois o país surge do encontro das diversidades. Porém, o grande desafio é fazer que oficialmente e publicamente, a construção da diversidade seja tratada no sistema educacional brasileiro (MUNANGA, 2014). Esse desafio apontado pelo antropólogo também é assinalado por

Revista Exitus, Santarém/PA, Vol. 9, № 5, p. 160 - 189, Edição Especial 2019. 
Canen (2006) diante de uma visão de um "mundo globalizado, tecnologizado, mas, ao mesmo tempo plural, constituído na diversidade de raças, etnias, gêneros, opções sexuais, religiões, linguagens e outros marcadores identitários" (CANEN, 2006, p. 35). Na perspectiva dos estudos culturais, as identidades que outrora eram reconhecidas como "fixas" e "estáveis" no que Hall (2014) identifica como "sujeito" do iluminismo, ou seja, uma construção essencialista do ser humano. O autor demonstra como o sujeito dado como possuidor de uma identidade essencialista, com as características ditas, anteriormente, muda de acordo com alguns teóricos para o sujeito pós-moderno, ou seja, de "identidade instável", "inacabada", "fragmentada" (Ibid., p. 28) e Laclau (2011) também comunga desta análise.

Hall (2014) demonstra esse processo de através de "cinco descentramentos" do sujeito cartesiano. Portanto, mediante essas proposições teóricas, Hall (2014) identifica o descentramento do sujeito, com isto, significa dizer que o sujeito pós-moderno se constitui de novas identidades, isto é, híbridas. Na frente de uma série de disputas pela terminologia "hibridismo", evocamos Canclini (2013) que aborda conceitualmente da seguinte maneira: "entendo por hibridação processos socioculturais, nos quais estruturas ou práticas discretas, que existiam de forma separada, se combinam para gerar novas estruturas, objetos e práticas" (CANCLINI, 2013, p.XIX). O que o autor chama de estruturas ou práticas discretas não são puras, pois já sofreram processos de hibridações. Assim, elementos culturais distintos que se atenuam formam um terceiro elemento que carrega parte dos elementos anteriores. Hall (2014) é categórico quando afirma: "A Europa Ocidental não tem qualquer nação que seja composta de apenas um único povo, uma única cultura ou etnia. As nações modernas são, todas, híbridos culturais" (HALL, 2014, p.36). E para esses processos múltiplos, diversos, plurais, nas dimensões culturais, sociais e

\footnotetext{
$91^{\circ}$ Às tradições do pensamento marxista; $2^{\circ} \mathrm{A}$ descoberta do inconsciente de Freud; $3^{\circ} \mathrm{A}$ linguística estruturalista de Saussure; $4^{\circ}$ No trabalho de Michel Foucault; $5^{\circ} \mathrm{O}$ movimento feminista.
}

Revista Exitus, Santarém/PA, Vol. 9, № 5, p. 160 - 189, Edição Especial 2019. 
históricas é que precisamos pensar no âmbito da construção do currículo, pois, "professores, gestores e autores devem combater a difusão de estereótipos e toda a forma de preconceito nos materiais didáticos [...] que constituem, historicamente, mecanismos de seleção, discriminação e exclusão" (GUIMARÃES, 2012 p. 69).

De acordo com Silva (2010), através da perspectiva pós-estruturalista não há uma teoria do currículo, mas um discurso que traz uma análise representacional. Sendo assim, não há, segundo essa perspectiva, um sentido engessado e essencializado sobre a definição de currículo. Ainda segundo Silva (2010), no âmbito pós-estruturalista "podemos dizer que o currículo é também uma questão de poder e que as teorias do currículo, na medida em que buscam dizer o que o currículo deve ser, não pode deixar de estar envolvidas em questões de poder" (SILVA, 2010, p.16). Em síntese, Silva (2010) aponta as características analisadas pelas teorias pós-críticas: "identidade, alteridade, diferença, subjetividade, significação e discurso, saber-poder, representação, cultura, gênero, raça, etnia, sexualidade, multiculturalismo" (Ibid., p.17). Sua percepção teórica a respeito do currículo é de suma relevância para o debate aqui escolhido ${ }^{10}$.

Dentre as diversas afirmações feitas por Silva (2010), utilizamos como prioritários neste artigo, os aspectos de currículo como território e relação de poder, o que corrobora com Arroyo (2011) e Apple (2011), sobretudo, na questão ideológica e política muito bem sinalizada por Apple (2011)11. O autor ainda discorre sobre a importância em formular a seguinte pergunta: "O conhecimento de quem vale mais?" (Ibid., p.50). Nesse jogo de poder, de ataques, de conflitos e interesses, ainda denomina que o currículo acaba transformando-se em uma espécie de bola de futebol política, ou seja, disputada partida a partida, jogo a jogo, ponto a ponto, numa competição

100 currículo é lugar, espaço, território. O currículo é relação de poder. O currículo é trajetória, viagem, percurso. O currículo é autobiografia, nossa vida, cirriculum vitae: no currículo se forja a nossa identidade. O currículo é texto, discurso, documento. O currículo é documento de identidade (SILVA, 2010, p.150).

"Não se trata 'apenas' de uma questão educacional, mas de uma questão intrinsecamente ideológica e política. Que reconheçamos ou não, o currículo e as questões educacionais sempre estiveram atreladas à história dos conflitos de classe, raça, sexo e religião, tanto nos Estados Unidos quanto em outros países (APPLE, 2011, p.49).

Revista Exitus, Santarém/PA, Vol. 9, № 5, p. 160 - 189, Edição Especial 2019. 
acirrada. Diante de políticas neoliberais ${ }^{12} q u e$ exercem pressões sobre o sistema educacional para que os objetivos empresariais e mercadológicos sejam os principais, quiçá, únicos, na formação escolar, tais questões são atribuídas de grande relevância na construção curricular. Na guerra ideológica exercida no contexto da política neoliberal, Apple (2011) assevera alguns importantes alertas para os educadores ${ }^{13}$. Tais exemplos expostos demonstram como todas as questões estão em jogo em uma gama de lutas políticas e sociais, sobretudo, a guerra ideológica na escola. A título de compreensão no âmbito do referencial teórico aqui discutido, ideologia é tratada da seguinte maneira: "[...] Está relacionada, principalmente, com os conceitos de linguagens do pensamento prático que estabilizam uma forma particular de poder e dominação; [...] acomodam as massas em seu lugar, subordinadas na formação social" (HALL, 2013, p.295). Outro alerta de vital relevância feito por Apple (2011) se refere para que tipo de conhecimento é legítimo, e que tipo de conhecimento é ilegítimo. Dito de outra maneira, qual conhecimento é considerado legítimo e verdadeiro, em detrimento de outros. Ou seja, a preocupação levantada também por Munanga (2014) e por diversos autores latinos, Lander et al (2005), no viés da desconstrução de um currículo monocultural e de sistema mundo, isto é, patriarcal, machista, sexista e eurocêntrico. Retomando aos alertas e as indagações de Apple (2011) na esfera ideológica, o currículo "trata dos interesses de quem? Quais as relações de poder estão em disputa?" (APPLE, 2011, p.49). Tais indagações,

\footnotetext{
${ }^{12}$ Neoliberalismo: doutrina que consiste em políticas de livre mercado, redução da ação do Estado na economia (Estado mínimo), forte estatização, entre outras características. Sugerimos o texto de Perry Anderson intitulado: Balanço do Neoliberalismo. Conferir na bibliografia.

${ }^{13}$ Os educadores vêm testemunhando um colossal esforço - que não se tem mostrado malsucedido - de exportação, para as escolas, da crise econômica e de relações de autoridade que afeta as práticas e políticas de grupos dominantes. Se as escolas, seus professores e seus currículos fossem mais rigidamente controlados, mais estreitamente vinculados às necessidades das empresas e das indústrias, mais tecnicamente orientados e mais fundamentados nos valores tradicionais e nas normas e regulamentos dos locais de trabalho, então os problemas de aproveitamento escolar, de desemprego, de deterioração das áreas centrais das grandes cidades etc. desapareceriam quase que por completo, assim querem nos convencer (APPLE, 2011, p. 50).
}

Revista Exitus, Santarém/PA, Vol. 9, № 5, p. 160 - 189, Edição Especial 2019. 
provocações e reflexões perpassam o nosso interesse, aqui discutido, na perspectiva da Lei 10.639/03.

Para encerrar esta seção, necessitamos abordar a questão da avaliação, principalmente, no quesito da obsessão avaliativa, pois as dimensões do ensino-aprendizagem são atravessadas pela avaliação.

A avaliação é um campo complexo e possui uma dimensão extensa, pois existem diversos tipos de avaliação. Entretanto, o que nos chama nossa atenção é a dimensão dos diversos indicadores de desempenho. O sistema de avaliação da educação brasileira é um conjunto de diversos programas. O Sistema de Avaliação da Educação Básica (SAEB), o Exame Nacional de Cursos (ENC), conhecido como Provão e, posteriormente, substituído pelo Exame Nacional de Desempenho do Ensino Superior (ENADE), o Exame Nacional de Jovens e Adultos (ENCEJA), o Sistema Nacional de Avaliação do Ensino Superior (SINAES), a Prova Brasil e o Índice de Desenvolvimento da Educação Básica (IDEB), Avaliação de Pós-Graduação (CAPES). Portanto, esse é o conjunto elencado por (CASTRO, 2009). Em seu artigo, a autora afirma que nos últimos quinze anos a política de avaliação educacional foi a que mais avançou no Brasil. A avaliação em larga escala nos parece ser uma tendência de inúmeros países para a compreensão dos processos e resultados dos sistemas educacionais.

Se tratando de avaliação, Afonso (2007) aponta para a crítica de todo esse processo que, na ânsia avaliativa dos sistemas educacionais não somente no Brasil, mas no mundo, conflagrou numa obsessão avaliativa. Na introdução de seu artigo, Afonso (2007) nos posiciona e contextualiza a respeito do cenário regulador da avaliação ${ }^{14}$. Esse protagonismo ressaltado

\footnotetext{
14Desde o início dos anos oitenta do séc. $X X$, temos vindo a assistir a um crescente protagonismo da avaliação como dispositivo de regulação dos sistemas de ensino e, mais recentemente, como dispositivo de regulação dos sistemas de administração pública. Num número crescente de países, e de uma forma mais explícita e intencional do que em outros momentos ou conjunturas históricas e sócio-políticas, a avaliação tem ampliado consideravelmente as suas fronteiras e diversificado a sua presença, passando a incidir não apenas em dimensões mais específicas das políticas educacionais (como as que têm dado grande centralidade à comparação nacional e internacional dos resultados acadêmicos dos estudantes), como, também, contribuindo para a definição, implementação e controle de outras políticas públicas (AFONSO, 2007, p.12).
} 
pelo autor redundou na obsessão avaliativa e que pela lógica de mercado do neoliberalismo introduz a questão que tange a "qualidade de ensino" e a "qualidade da educação", discursos que são reproduzidos incansavelmente pela ideologia de uma educação mercadológica. No viés das políticas educacionais, no que se refere à "qualidade de ensino", tema polêmico e controvertido entre os especialistas, por este motivo optamos por colocar entre aspas, pois afinal, o que é ensino de qualidade? O que é uma educação de qualidade? Para Candau (2013) "Trata de uma expressão polissêmica, de um conceito socialmente construído e em constante reformulação, que suscita fortes polêmicas e debates entre os educadores e educadoras na sociedade" (CANDAU, 2013, p.10,11).

Para Afonso (2007), o discurso da "qualidade da educação" torna-se reducionista, pois, através de mecanismos instrumentais, ou seja, um processo de racionalização quantificável, que escamoteia e invibiliza "políticas educacionais, os sujeitos e os respectivos processos e contextos educativos" (p. 18). Em síntese, uma elitização e uma seletividade na trajetória do discurso da meritocracia.

Frente à crítica tecida pelo autor, chama a nossa atenção, sobretudo, a respeito da educação como mercadoria na dimensão da cosmovisão neoliberal e sua consequência, ou seja, a produção de uma elitização do sistema de seletividade social, isto é, exclusão. Portanto, é diante de tamanho desafio, de preferência nos dias atuais, que nos preocupamos com as questões demandadas das relações étnico-raciais na construção de um currículo que abarque a diversidade, o antirracismo, o contrapoder, para que certos autores-sujeitos, numa perspectiva de autonomia e emancipação não sejam cerceados em prol de objetivos ideológicos de mercado (AFONSO, 2007). A lógica pautada pela política neoliberal de acordo com Souza (2003) gera "[...] o fortalecimento dos mecanismos discriminatórios" (p.188), e amplia a discussão no âmbito da lógica mercadológica ${ }^{15}$.

\footnotetext{
${ }^{15} \mathrm{O}$ princípio é o de que a avaliação gera competição e a competição gera qualidade. Nesta perspectiva assume o Estado a função de estimular a produção dessa qualidade. As
}

Revista Exitus, Santarém/PA, Vol. 9, № 5, P. 160 - 189, Edição Especial 2019. 
A educação como mercadoria no bojo da ideologia neoliberal cria, discursivamente, a competição. Pressupondo atingir metas e objetivos no lastro de um padrão de qualidade de ensino e educação. Entretanto, de acordo com os autores (as) aqui consultados (AFONSO, 2007; APPLE, 2011; MUNANGA, 2014; SOUZA, 2003), observamos que tais pressupostos operam como um escamoteamento para a exclusão. Cabe uma ressalva, tanto Afonso (2007) como Souza (2003) não se opõem a avaliação, mas como é realizada. Portanto, o que impera é o nexo de uma visão educacional como mercadoria gerida por uma lógica produtivista, meritocrática, onde o ambiente competitivo é estimulado e a recompensa recai para os profissionais que assim acessam os resultados predeterminados pelo sistema. Nessa ambiência competitiva que recompensa os "melhores" ou, dito de outra maneira, os que atingem as "metas", sempre haverá um escamoteamento de informações. Nesse sentido, ou seja, para a percepção de Sennett (2009), se referindo à baixa motivação e desmoralização dos trabalhadores.

\section{Currículo: possibilidades e desafios contra-hegemônicos}

É importante ressaltar (ainda que pareça óbvio) que quando discutimos currículo, intrinsecamente, a instituição escolar aparece como atravessamento. E de acordo com o suporte teórico aqui tratado (críticos e pós-críticos das teorias do currículo), que se opõem as teorias tradicionais, não entendem a escola como apenas mera reprodução social, no sentido defendido por Bourdieu e Passeron (1975) ${ }^{16}$. Entretanto, diante da crítica aqui posicionada pelos autores à obra "A Reprodução", de forma alguma, negamos a importância das monumentais pesquisas e constribuições no campo da sociologia da educação, sobretudo, realizadas pela equipe de

políticas educacionais ao contemplarem em sua formulação e realização a comparação, a classificação e a seleção incorporam, conseqüentemente, como inerente aos seus resultados a exclusão, o que é incompatível com o direito de todos à educação (SOUZA, 2003, p.188).

${ }^{16}$ BOURDIEU, P. PASSERON, Jean-Claude. A Reprodução: Elementos para uma teoria do sistema de ensino. Rio de Janeiro: Livraria Francisco Alves Editora S.A., 1975. 
Pierre Bourdieu. Dito isto, a visão proposta pelos autores é de uma pedagogia da possibilidade. Sendo assim, Gomes (2010) propõe uma pedagogia da diversidade, Gentili (2008) uma pedagogia da esperança, Giroux e McLaren (2011) uma pedagogia da possibilidade e da contraesfera ou contra-hegemônica, no âmbito de um imaginário radical ${ }^{17}$. As mediações apontadas pelos autores, no que tange à pedagogia da possibilidade, sugerem ações na dimensão da instituição escolar e do currículo contra os desígnios do poder e do controle. Silva (2010), analisando a pedagogia da possibilidade sinaliza que: "[...] Deve haver um lugar para a oposição e a resistência para a rebelião e subversão" (SILVA, 2010, p.53). A resistência referida por Silva (2010) e o conceito de possibilidade de Giroux e McLaren (2011), nos conduz a reflexão no âmbito da Lei 10.639/03, sua relevância como política pública para inserção de conteúdos que possibilitem articulações contra-hegemônicas, pois, o currículo também cria e produz sentidos sociais ${ }^{18}$. Levando em consideração as ponderações destacadas em nota, o currículo como campo de construção de desigualdades outrora poder-se-á ser desconstruído e (re)construído como possibilidade de inclusão social, política, cultural e econômica.

Diante da construção anti-hegemônica no âmbito do currículo tornase necessário, neste momento, pontuar a questão do multiculturalismo, devido à postura teórica aqui adotada. Mesmo mediante uma série de críticas tecidas sobre o multiculturalismo, no sentido de doutrina política e suas reduções, Hall (2013) levanta as seguintes indagações: "Pode um conceito que significa tantas coisas diferentes e que tão efetivamente acirra os ânimos de inimigos tão diversos e contraditórios, ter realmente algo a

\footnotetext{
${ }^{17} \mathrm{Em}$ nosso caso, um imaginário radical representa um discurso que oferece novas possibilidades para o desenvolvimento de relações sociais democráticas; estabelece elos entre o político e o pedagógico, a fim de incentivar o desenvolvimento de contraesferas públicas que se engajem seriamente em articulações e práticas da democracia radical e se comprometam com elas (GIROUX; MACLAREN, 2011, p.146).

${ }^{18} \mathrm{O}$ currículo não está simplesmente envolvido com a transmissão de fatos e conhecimentos objetivos. O currículo é o local onde, ativamente, se produzem e criam significados sociais. [...] Esses estão estreitamente ligados a relações sociais de poder e desigualdade. Trata-se de significados de disputas de significados que são impostos, mas também contestados (SILVA, 2010, p. 55,56).
}

Revista Exitus, Santarém/PA, Vol. 9, № 5, p. 160 - 189, Edição Especial 2019. 
dizer"? Por outro lado, sua condição contestada não constitui, precisamente, seu valor? (HALL, 2013, p.59). Nesse tufão de disputas conceituais, Stuart Hall assevera: "Por bem ou por mal, estamos inevitavelmente implicados em suas práticas, que caracterizam e definem as sociedades da modernidade tardia" (Ibid., p.60). Santos e Nunes (2003) reconhecem as contestações do conceito e a constituição explícita das disputas no terreno político. Hall (2013) descreve os diversos tipos de multiculturalismos, que para uma visão ampla e detalhada das disputas conceituais, julgamos interessante destacar ${ }^{19}$. Perante tantas adjetivações Andrade (2009), traz uma simples definição: "é a constatação de um fenômeno que envolve a convivência e a coexistência de diversas culturas, num mesmo território e num mesmo tempo histórico" (ANDRADE, 2009, p. 17).

Numa perspectiva educacional das relações étnico-raciais e no âmbito do currículo tratado neste artigo, nossa opção se configura pelo posicionamento do multiculturalismo de acordo com McLaren (2000), isto é, o crítico ou revolucionário, função atribuída ao movimento de resistência à dominação do poder estabelecido. Em entrevista no Brasil, assim disse o autor: "O capitalismo precede o racismo" (MCLAREN, 1999, s/p). Este conceito também é operado por Kellner (2011) que nos chama a atenção e assinala "[...] a sociedade e a cultura contemporânea constituem um terreno de lutas [...]" (KELLNER, 2011, p.125). O autor em seu estudo cultural

\footnotetext{
19 Multiculturalismo conservador - insiste na assimilação da diferença às tradições e costumes da maioria; Multiculturalismo liberal - busca integrar os diferentes grupos culturais o mais rápido possível ao mainstream, ou sociedade majoritária, baseada em uma cidadania individual e universal, tolerando certas práticas culturais particularistas apenas no domínio privado; Multiculturalismo pluralista - avaliza as diferenças grupais em terrenos culturais e concede direitos de grupo distinto a diferentes comunidades de uma ordem política comunitária ou mais comunal; Multiculturalismo comercial - pressupõe que, se a diversidade dos indivíduos de distintas comunidades for publicamente reconhecida, então os problemas de diferença cultural serão resolvidos (e dissolvidos) no consumo privado, sem qualquer necessidade de redistribuição de poder e dos recursos; Multiculturalismo corporativo - (público ou privado) busca "administrar" as diferenças culturais da minoria, visando os interesses do centro; Multiculturalismo crítico ou revolucionário - enfoca o poder, o privilégio, a hierarquia das agressões e os movimentos de resistência (HALL, 2013, p.58).
} 
crítico faz algumas afirmações que nos auxiliam na compreensão de determinados grupos 20 .

O estudo cultural crítico e a teoria social são multiculturais, pois analisam as diferenças, a diversidade cultural e a alteridade (KELLNER, 2011). O termo multicultural é entendido para o autor como um conceito geral para as múltiplas manifestações em estudos culturais que "[...] insistam na importância de examinar minuciosamente representações de classe, sexo, sexualidade, etnia, subalternidade e outros fenômenos [...]" (KELLNER, 2011, p.126). Ainda aponta que: "Os cânones da cultura masculina, branca e europeia foram desafiados, e um amplo espectro vozes e indivíduos novos ficou sendo conhecido" (Ibid., p.127). Portanto, seja na alcunha do multiculturalismo insurgente de Kellner (2011) ou revolucionário para Giroux e McLaren (2011), a questão perpassa nas análises críticas a respeito das diferenças, sobretudo, sobre as desigualdades, opressões, lutas, resistências, e nesse sentido, no esteio do multiculturalismo insurgente ou revolucionário está nosso mestre Paulo Freire na pedagogia do oprimido (KELLNER, 2011).

Santos e Nunes (2003) diante das críticas ao conceito de multiculturalismo propõem o multiculturalismo emancipatório, porém, afirmam que nem todo multiculturalismo é emancipatório. "As versões emancipatórias do multiculturalismo, baseiam-se no reconhecimento da diferença e do direito à diferença e da coexistência ou construção de uma vida em comum além das diferenças de vários tipos" (SANTOS; NUNES, 2003, p.33). "Esta visão alternativa vai buscar no marxismo a ideia da importância das ligações internacionais das lutas no quadro do capitalismo como sistema global" (Ibid., p.35). Porém, segundo os autores, a clássica visão de se ter um ator coletivo, o proletariado global, é reconceitualizado para uma correspondente diversidade de sujeitos coletivos. O antagonismo provocado pela luta de classe, já não é o ponto privilegiado contra o sistema. "São os

\footnotetext{
${ }^{20} \mathrm{O}$ estudo cultural crítico adota normas e valores com os quais critica textos, produções e condições que promovam opressão e dominação. Valoriza positivamente fenômenos que promovam a liberdade humana, a democracia, a individualidade e outros valores que, por ele adotados, são defendidos e valorizados em estudos e situações concretas (KELLNER, 2011, p.125).
}

Revista Exitus, Santarém/PA, Vol. 9, № 5, p. 160 - 189, Edição Especial 2019. 
próprios processos do capitalismo que geram contradições e lutas de diferentes tipos, que não são todas simplesmente integráveis aos subordináveis à luta de classes, e que não tem, necessariamente, o espaço nacional como espaço privilegiado" (Ibid., p.35). Os autores apontam ${ }^{21}$ outras dimensões para além da clássica análise da luta de classe.

$\mathrm{Na}$ medida em que pensamos sobre as ressalvas apontadas pelos autores, no compromisso da construção de uma sociedade democrática, inclusiva, que articule políticas de igualdade e diversidade, Candau (2014) abraça teoricamente o multiculturalismo interativo, também conhecido como interculturalidade, ou seja, tanto o revolucionário quanto o interativo são tratados aqui como uma escolha teórica no pressuposto de possibilitar a construção de currículo para abarcar as relações étnico-raciais, na perspectiva de uma educação antirracista, igualitária, plural e diversa. Candau (2014) recorre à classificação de Catherine Walsh22, no que se refere às três concepções principais de educação intercultural: relacional, funcional e crítica. Abordagens apresentadas como arcabouço e que se multiplicam em inúmeros pareceres. Entretanto, tratamos segundo Candau (2014), o aspecto da interculturalidade crítica ${ }^{23}$.

Consideramos de vital importância, o debate da construção do currículo neste espectro, para a constituição de uma educação contrahegemônica. Nesse sentido, as características da perspectiva da interculturalidade que "fortalece a construção de identidades dinâmicas, abertas e plurais, assim como questiona uma visão essencializada de sua constituição" (Ibid.,p.32). Outra característica de suma relevância para as

\footnotetext{
${ }^{21}$ As lutas das mulheres, dos ambientalistas, dos movimentos anti-racistas ou pelo reconhecimento de identidades étnicas estão aí para nos recordar que tanto a dominação quanto a resistência se fazem ao longo de diversos eixos, e que não estão subordinados, de maneira definitiva, a uma "contradição principal". Em diferentes situações irão emergir lutas diversas e atores coletivos distintos (SANTOS; NUNES, 2003, p.35).

${ }^{22}$ Professora da Universidad Andina Simon Bolívar (sede Equador) especialista no tema.

${ }^{23}$ Trata-se de questionaras diferenças e desigualdades construídas ao longo da história entre diferentes grupos socioculturais, étnico-raciais, de gênero, orientação sexual, entre outros. Parte-se da afirmação de que ainterculturalidade aponta à construção de sociedades que assumam as diferenças como constitutivas da democracia e sejam capazes de construir relações novas, verdadeiramente igualitárias, entre os diferentes grupos socioculturais, o que supõe empoderar aqueles que foram historicamente inferiorizados (CANDAU, 2014, p.28).
}

Revista Exitus, Santarém/PA, Vol. 9, № 5, p. 160 - 189, Edição Especial 2019. 
relações étnico-raciais: "Potencia os processos de empoderamento, principalmente, de sujeitos e atores inferiorizados e subalternizados e a construção da autoestima, assim como, estimula a construção da autonomia, num horizonte de emancipação social" (Ibid., p.32). É importante lembrar que a igualdade não se opõe à diferença. Santos (2003) aborda uma solução clássica para a falsa oposição: "As pessoas e os grupos sociais tem o direito a ser iguais quando a diferença os inferioriza, e o direito a ser diferentes quando a igualdade os caracteriza" (SANTOS, 2003, p.56). Para Andrade (2009) é impossível uma uniformização cultural e a solução está na diferença, como resistência às padronizações homogeneizantes. Entretanto, o autor compreende que não há espaço para a ingenuidade, esse é um território de disputa e marcado pelas relações de poder (ANDRADE, 2009). Assim dito, e diante das possibilidades e desafios, a construção do currículo, numa perspectiva anti-hegemônica, dar-se-á como bem nos alertou Andrade (2009) em um território de disputa, assim como (APPLE, 2011; ARROYO, 2011; SILVA, 2010; GIROUX; MCLAREN, 2011; CANDAU, 2014; MUNANGA, 2014). De maneira que impera o nexo de uma visão educacional como mercadoria gerida por uma lógica produtivista, pressupondo atingir metas e objetivos para um padrão de qualidade de ensino e educação. Neste momento, ressaltamos os embates e disputas atuais no que abarca as propostas do "Movimento Escola sem Partido" (MESP).

E para corroborar com a lógica mercantilista, mencionada anteriormente, Penna (2017) sinaliza a fala do coordenador do (MESP) ${ }^{24}$. Para além do cumprimento de metas e objetivos produtivistas, temos neste movimento, o alinhamento neoliberal da lógica de mercado. O aluno é idealizado como consumidor e a escola fornecedora de um produto consumível no viés discursivo para a "melhoria" da "qualidade" da

\footnotetext{
${ }^{24} \mathrm{O}$ nosso projeto foi inspirado no código de defesa do consumidor. O Código de Defesa do Consumidor intervém na relação entre fornecedores e consumidores para proteger a parte mais fraca, que é o consumidor, o tomador de serviços que são prestados pelos fornecedores. Da mesma maneira, a nossa proposta ela intervém na relação de ensinoaprendizagem para proteger a parte mais fraca dessa relação que é o estudante, aquele indivíduo que é vulnerável, que está se desenvolvendo (PENNA, 2017 p 39).
} 
educação. Essa perspectiva descrita por Souza (2003) é uma dentre diversas perspectivas e concepções sobre a qualidade da educação (CANDAU, 2013).

\section{Um breve relato: algumas questões de história aplicadas nas instituições escolares da rede estadual do Rio de Janeiro}

Como discutido anteriormente neste texto, a respeito do sistema de avaliação da educação brasileira, O SAERJINHO integrou o sistema de avaliação externa do estado do Rio de Janeiro, denominado de SAERJ que vigorou até 2017. O SAERJ era composto de dois programas de avaliação: a avaliação externa aplicada anualmente no final do período letivo (SAERJ) e a avaliação diagnóstica do desempenho escolar, aplicada no final de cada bimestre (SAERJINHO). Implementado em 2011 pela Secretaria de Estado de Educação do Rio de Janeiro (SEEDUC/RJ) e o Centro de Políticas Públicas e Avaliação da Educação (CAED) que se responsabilizou pela elaboração das provas, dos gabaritos, da matriz curricular e análise dos dados.

Para analisar as questões de história, antes, torna-se necessário justificar o rescorte aqui tratado. Destacamos os cadernos de avaliação do SAERJINHO de 2013 e 2014. As questões da disciplina história foram contempladas somente no Ensino Médio a partir de 2013. A delimitação ao ano de 2014 reside no quesito da não disponibilização do material no sistema ${ }^{25}$.

Diante do componente curricular (Antiguidade) percebemos uma invisibilidade para a História da África Antiga, ou seja, tanto no caderno de 2013 quanto de 2014, os componentes clássicos (Grécia e Roma) permaneceram hegemônicos. Portanto, negando a discussão sobre o território africano como importante fonte para a história da humanidade (LIMA, 2006). Entretanto, como potência para a desconstrução dos discursos curriculares hegemônicos, destaca-se a questão de no 31 da prova de 2014 , $1^{\circ}$ ano, $3^{\circ}$ bimestre, eixo temático - Expansão Marítima:

25 Disponínel em: http://www.avaliacaoexternasaeri.caedufff.net/o-sistema-estadual/osaerjinho/apresentacao/. Acesso em: 20 de janeiro de 2018. 
Leia o texto abaixo.

\section{Império de Mali}

Expandiu-se por volta do século XII. As cidades de Tumbuctu, Gao e Djene eram importantes centros universitários e culturais. O povo Dogon que habitava a região registrou em monumentos as luas de Júpiter, os anéis de Saturno e a estrutura espiral da Via Láctea, observações feitas a partir do século XVII na Europa.

Disponivel em:_http://revistaescola.abril.com.br/swflanimacoes/exibi-animacao.shtml?187_africa_info.swł>. Acesso em: 9 dez. 2013.

Esse texto descreve conhecimentos dos habitantes do Império de Mali na ârea da
A) agricultura
B) arquitetura.
C) astronomia.
D) irrigação.
E) metalurgia.

A questão nos possibilita trilhar caminhos anti-hegemônicos, isto é, na descontrução curricular eurocêntrica, especialmente, nas reduções construídas pelo Ocidente, ou seja, como o centro do conhecimento científico (SANTOS, 2010). O enucniado assinala a palavra conhecimento, isto é, a produção do conhecimento e o desenvolvimento da astronomia no continente africano são precedentes ao continente europeu. O texto de apoio descreve o desenvolvimento das cidades no âmbito da produção e da construção dos centros universitários e culturais. As relações entre conhecimento, cultura e ciência são de extrema relevância para o debate da pluralidade de saberes (SANTOS, 2010), na questão em tela. Uma potência emancipadora e contra-hegemônica (GIROUX; MAcLAREN, 2011; APPLE, 2011).

Leia o texto abaixo.

[...] No século XIX, a África foi toda dividida entre os países imperialistas que buscavam matérias-primas e zonas de influência no continente. A divisão do território foi feita sem levar em consideração as diferenças étnicas em cada região, deixando, muitas vezes, grupos rivais, ou, pelo menos, de práticas culturais muito distintas vivendo em um mesmo território. As consequências desse processo são vistas até hoje, marcando os grandes problemas de instabilidade social e política no continente. [...]

Disponivel em: <http://www.infoescola.com/historial>. Acesso em: 15 abr. 2012. Fragmento. *Adaptado: Reforma Ortográfica.

De acordo com esse texto, o que o imperialismo europeu acarretou para os territórios ocupados?
A) Conflitos étnicos.
B) Distribuição de riquezas.
C) Erradicação da fome.
D) Estabilidade econômica
E) Valorização cultural.

Revista Exitus, Santarém/PA, Vol. 9, № 5, p. 160 - 189, Edição Especial 2019. 
O texto aponta uma das artimanhas ideológicas colocadas em prática pelos imperialistas europeus. A questão possibilita o debate, a reflexão, as habilidades comparativas, sobretudo, a respeito dos atuais conflitos em detreminadas regiões do continente africano. A utilização do recurso (cinema/filme) em sala de aula, especialmente, no contexto da disciplina história dar-se-á de enorme valor didático. Nesse sentido, como ferramenta pedagógica temos o título: Hotel em Ruanda de 2004 (EUA, Itália, África do Sul - $120 \mathrm{~min}$ ). Em síntese, traz a discussão da guerra civil em Ruanda onde os hutus matam os tutis, chegando perto de um milhão de pessoas assassinadas. Uma das consequências do processo de colonização belga que fomentou rivalidades entre as duas etinias acirrando um discurso de ódio.

\section{Leia o texto abaixo.}

[...] Em 1956 foi criado o Movimento Popular pela Libertação de Angola (MPLA), sob a liderança de Agostinho Neto. Posteriormente surgiram a Frente Nacional de Libertação de Angola e a União Nacional para a Libertaçã́o Total de Angola (UNITA) [...] a independência de Moçambique foi patrocinada pela Frelimo (Frente de Libertação de Moçambique), tendo como líder Samora Machel, que em 1960 iniciou um movimento de guerrilha. [...] No ano 1956 Amilcar Cabral fundou o Partido Africano para a independência da Guiné e Cabo Verde (PAIGC). No ano de 1974 foi reconhecida a independência da Guiné; em 1975 do Cabo Verde e São Tomé e Príncipe.

JUNIOR, Armando Viana. A Descolonizaçấo. Disponivelem: <hittp://wwwohistoriador.com.br/historia-contemporaneal>. Acesso em: 3 dez. 2013. Fragmento.

Esse texto descreve movimentos de independência em relação
A) à Bélgica.
B) à França.
C) à Holanda.
D) à Inglaterra.
E) a Portugal.

O fragmento acima é retirado de um blog denominado de "O historiador", inicia o seu breve relato sobre a descolonização como o seguinte título: "Causas da descolonização". O autor aponta para duas causas. A primeira, a respeito das crises dos países europeus devido a segunda grande guerra e a segunda, com a consciência nacionalista por parte de ulguns líderes africanos. Com base nas principais produções historiográficas, especialmente, dos especialistas em história 
contemporânea, as relações traçadas pela questão supracitada não estão equivocadas (HERNANDEZ, 2008). No entanto, a questão possibilita como potência, a discussão das narrativas que valorizam a luta e a resistência das lideranças negras, sobretudo contra as ideologias dominantes capitalistas, excludentes e racistas, pois o comando da questão torna este contexto esvaziado. O sentido da questão aponta para uma perspectiva onde 0 eurocentrismo é reforçado. Lima (2006) nos permite um exemplo de como a valorização poder-se-ia operacionalizar no comando da questão, caso levasse em consideração os "[...] protagonistas na sua própria terra, líderes africanos [...] se destacaram no cenário internacional, intelectuais e acadêmicos africanos encaminharam a reescritura da história de seus países e regiões" (p. 103). Constata-se a potencialidade em que a descrição do texto possibilita ser trabalhada, principalmente, em sala de aula de maneira que provoque uma discussão emancipadora, rompendo com equívocos de narrativas que "[...] identificam os ovimentos de resistência como de pequena envergadura, desorganizados [...] consideradas insignificantes, não apresentando consequências importantes para o seu tempo" (HERNANDEZ, 2008 p. 1 10). Portanto, percebe-se neste contexto a importância do ofício do professor como mediador em sala de aula, sobretudo da disciplina de história no caso tratado neste texto.

\section{Considerações finais: contribuições e possibilidades}

$\mathrm{Na}$ perspectiva teórica em que transitamos não nos permite fazer nenhum tipo de afirmação ou conclusão fechada, ou seja, temos a consciência que a porta está aberta ou, melhor dizendo, entreaberta, e em constante mudança, sobretudo, devido às constantes disputas e as relações de poder, principalmente, se tratando de políticas públicas e no atual cenário da política brasileira, onde a extrema direita adentra o poder presidencial com o seu candidato eleito, permeado discursivamente no processo, através de falas racistas, homofóbicas, machistas, sexistas, isto é, totalitárias. 
Traçamos uma discussão sobre o indispensável conceito de "raça" e racismo, no viés sociológico e político de acordo com Munanga (2012), Hall (2013), Appiah (1997), lanni (2004), Guimarães (2012), Domingues (2004), Skidmore (2012), Schwarcz (1993) e Hall (2013).

No que tange à dimensão do currículo, tratamos o debate como um território de disputa Arroyo (2011), currículo como um espaço sem neutralidade e de relações de poder Apple (2011), uma breve discussão sobre as principais teorias do currículo através de Silva (2010), articulado com posturas que defendem uma construção por uma pedagogia emancipatória, Gomes (2010), por uma pedagogia da diversidade Gomes (2010), Munanga (2010), por uma pedagogia da possibilidade Giroux e McLaren (2011). As adjetivações do multiculturalismo Kellner (2011), Hall (2013), McLaren (2000), Candau (2014). O aspecto insurgente ou revolucionário Giroux e McLaren (2011) e a interculturalidade Candau (2014), no sentido de uma construção anti-hegemônica.

Diante do currículo como um campo-território de disputa, sem neutralidade, das relações de poder, sobretudo, dos padrões hegemônicos do sistema-mundo, ou seja, (machista, patriarcal e eurocentrado), podemos influir que, a partir da Lei 10.639/03, a construção de um currículo que possibilite a (re)construção de uma sociedade que assuma as diferenças, a diversidade, como uma constituição enriquecedora na dimensão de uma sociedade democrática e de novas relações, mostrou-se frutuosa e com enormes desafios e possibilidades, principalmente, no empoderamento a respeito dos grupos que foram inferiorizados e subalternizados no processo histórico.

Constatamos que mesmo diante das invisibilidades e negações persistentes na esfera curricular, sobretudo, no caderno de avaliação do SAERJINHO (2013-2014), vislumbra-se enormes potenciais para o debate antirracista e antieurocêntrico. Sendo assim, mesmo de maneira incompleta, imperfeita e aberta, prosseguimos e resistimos para a construção de uma pedagogia da esperança, diversa, inclusiva e contra-hegemônica, diante de um cenário que nos cerca de maneira assombrosa, unilateral, 
monocultural e totalitária. Sendo assim, diante das construções teóricas elencadas e discutidas neste texto, apontamos como possibilidade no âmbito educacional, uma pedagogia da diversidade.

Uma pedagogia da diversidade no viés intercultural está comprometida para a construção de uma sociedade democrática, que busca a equidade, que trabalha em prol do reconhecimento dos diferentes grupos socioculturais. Integra o comprometimento e prática pedagógica que reconhece a diferença, não como um problema, mas como potencial para novas relações e que tais relações seja igualitárias entre a diversidade, sobretudo focando no empoderamento dos sujeitos que foram invisibilizados, negados, calados, subalternizados no processo histórico.

Uma pedagogia da diversidade em tais dimensões proporciona 0 diálogo entre os diversos saberes, estabelecendo uma posição antihegemônica, resistindo e desconstruindo as narrativas monoculturais. Trabalha a tensão epistemológica constituída entre universal versus relativismo.

\section{REFERÊNCIAS}

AFONSO, A. J. Estado, Políticas Educacionais e Obsessão Avaliativa.

Contrapontos - Volume 7, n.1.P. 11-22, Itajaí, jan/abr, 2007.

ALBERTI, $V$. Algumas estratégias para o ensino de história e cultura afrobrasileira. In: MONTEIRO, A. M. PEREIRA, A. A. (Orgs.). Ensino de História e Culturas Afro-Brasileiras e Indígenas. Rio de Janeiro: Pallas, 2013.

ANDRADE, M. A diferença que desafia a escola: Apontamentos iniciais sobre a prática pedagógica e a perspectiva intercultural. In: ANDRADE, M. (Org.). A diferença que desafia a escola: a prática pedagógica e a perspectiva intercultural. Rio de Janeiro: Quartet, 2009.

APPIAH, K. A. Na casa de meu pai. Rio de Janeiro: Contraponto, 1997.

APPLE, M. Repensando a ideologia e currículo. In: MOREIRA, A. F. SILVA, T. T. (Orgs.). Currículo, Cultura e Sociedade. São Paulo: Cortez, 2011.

APPLE, M. Ideologia e Currículo. São Paulo: Brasiliense, 1982. 
ARROYO, M. G. Currículo, território em disputa. Petrópolis, Rio de Janeiro: Vozes, 2011.

ARROYO, M. G. A pedagogia multirracial popular e o sistema escolar. In: GOMES, Nilma Lino (Org.). Um olhar para além das fronteiras: educação e relações raciais. Belo Horizonte: Autêntica, 2010.

BOURDIEU, P.; PASSERON, J-C. A reprodução: elementos para uma teoria do sistema de ensino. Rio de Janeiro: Livraria Francisco Alves S.A., 1975.

BRASIL. Plano Nacional de Implementação das Diretrizes Curriculares Nacionais para a Educação das Relações Étnico-Raciais e para o Ensino de História e Cultura Afro-Brasileira e Africana. Ministério da Educação, Secretaria de Educação Continuada, Alfabetização, Diversidade e Inclusão. Brasilia: MEC, SECADI, 2013.

CANCLINI, N. G. Culturas Híbridas: estratégias para entrar e sair da modernidade. São Paulo: EDUSP, 2013.

CANDAU, V. Educação Intercultural: entre afirmações e desafios. In: CANDAU, V. MOREIRA, A. F. (Orgs.). Currículos, disciplinas escolares e culturas. Petrópolis, Rio de Janeiro, 2014.

CANDAU, V. Currículo, Didática e Formação de Professores: uma teia de ideias força e perspectiva de futuro. In: OLIVEIRA, M. R.; PACHECO, J. A. (Orgs.). Currículo, Didática e Formação de Professores. Campinas, São Paulo: Papirus, 2013.

CANEN, A. Multiculturalismo e identidade escolar: desafios e perspectivas para repensar a cultura escolar. In: OLIVEIRA, I. (Org.). Caderno Penesb volb. Niterói, Rio de Janeiro: EDUFF, 2006.

CASTRO, M. H. G. de. Sistemas de Avaliação e Educação no Brasil: avanços e novos desafios. São Paulo em Perspectiva. Vol.23, n1, jan/jun, 2009.

CASHMORE, E. Dicionário de relações étnicas e raciais. São Paulo: Selo Negro, 2000.

COELHO, W. de N. B.; MÜLLER, T. M. P. (Orgs.). Relações Étnico-Raciais e Diversidade. Niterói, Rio de Janeiro: Editora da UFF, Alternativa, 2014.

CORONIL, F. Natureza do pós-colonialismo: do eurocentrismo ao globocentrismo. In: LANDER, E. (Org.). A colonialidade do saber: eurocentrismo e perspectiva latino-americanas. Buenos Aires: CLACSO, 2005.

DOMINGUES, P. Uma História não contada: negro, racismo e branqueamento em São Paulo no pós-abolição. São Paulo: Editora SENAC, 2004. 
DUSSEL, H. Europa, modernidade e eurocentrismo. In: LANDER, Edgardo (Org.). A colonialidade do saber: eurocentrismo e perspectiva latinoamericanas. Buenos Aires: CLACSO, 2005.

ESCOBAR, A. O lugar da natureza e a natureza do lugar: globalização ou pós-desenvolvimento? In: LANDER, E. (Org.). A colonialidade do saber: eurocentrismo e perspectiva latino-americanas. Buenos Aires: CLACSO, 2005.

FREIRE, P. Pedagogia do Oprimido. Rio de Janeiro: Paz e Terra, 2014.

GENTILI, P. Desencanto e Utopia: a educação no labirinto dos novos tempos. Petrópolis, Rio de Janeiro: Vozes, 2008.

GIROUX, H. A.; MCLAREN, P. Formação do professor como uma contraesfera pública: a pedagogia radical como uma forma de política cultural. In: MOREIRA, A. F.; SILVA, T. T. (Orgs.). Currículo, Cultura e Sociedade. São Paulo: Cortez, 2011.

GONÇALVES, M. A. R. Diversidade: a cultura afro-brasileira e a Lei 10.639/03. In: SOUZA, M. H. V. (Org.). Relações raciais no cotidiano escolar: diálogos com a Lei 10.639/03. Rio de Janeiro: Rovelle, 2009.

GOMES, N. L. Diversidade étnico-racial e educação no contexto brasileiro: algumas reflexões. In: GOMES, N. L. (Org.). Um olhar para além das fronteiras: educação e relações raciais. Belo Horizonte: Autêntica, 2010.

GUIMARÃES, A. S. A. Classes, raças e democracia. São Paulo: Editora 34, 2012.

HALL, S. Da diáspora: identidades e mediações culturais. Belo Horizonte: Editora UFMG, 2013.

HALL, S. A identidade cultural na pós-modernidade. Rio de Janeiro: Lamparina, 2014.

HERNADEZ, L. L. A África na sla de aula: visita à história contemporânea. São Paulo: Selo Negro, 2008.

IANNI, O. Raças e classes sociais no Brasil. São Paulo: Brasiliense, 2004.

KELLNER, D. A cultura da mídia. Estudos culturais: identidade e política entre o moderno e pós-moderno. São Paulo: EDUSC, 2011.

LACLAU, E. Emancipação e Diferença. Rio de Janeiro: EDUERJ, 2011. 
LANDER, E. A colonialidade do saber: eurocentrismo e perspectiva latinoamericanas. Buenos Aires: CLACSO, 2005.

LIMA, M. História da África: temas e questões para a sala de aula. In: OLIVEIRA, I. SISS, A. (orgs.). Caderno do Penesb vol 7. Rio de Janeiro, Niterói: EDUFF, 2006. P.73-105.

MCLAREN, P. Multiculturalismo revolucionário: pedagogia do dissenso para o novo milênio. Porto Alegre: Artmed, 2000.

MCLAREN, P. Pela abolição da brancura. Entrevistado por Dóris Fialcoff. Jornal Extra Classe, porto Alegre, ano 4, n.36, 1999. Disponível em: www.simpro-rs.or/extra/out99/entrevista.htm. Acesso em: 20 de outro de 2016.

MIGNOLO, W. A colonialidade de cabo a rabo: o hemisfério ocidental no horizonte conceitual da modernidade. In: LANDER, E. A colonialidade do saber: eurocentrismo e perspectiva latino-americanas. Buenos Aires: CLACSO, 2005.

MORENO, A. Superar a exclusão, conquistar a equidade: reformas políticas e capacidades no âmbito social. In: LANDER, E. A colonialidade do saber: eurocentrismo e perspectiva latino-americanas. Buenos Aires: CLACSO, 2005.

MUNANGA, K. Negritude: usos e sentidos. Belo Horizonte: Autêntica, 2012.

MUNANGA, K. Educação e diversidade étnico-racial: a importância da história do negro e da África no sistema educativo brasileiro. In: COELHO, W. N. B. MÜLLER, T. M. P. (Orgs.). Relações étnico-raciais e diversidade. Niterói, Rio de Janeiro: Editora da UFF, 2014.

NUNES, J. A.; SANTOS, B. de S. Introdução: para ampliar o cânone do reconhecimento, da diferença e da igualdade. (Org.). Reconhecer para libertar: os caminhos do cosmopolitismo multicultural. Rio de Janeiro: Civilização Brasileira, 2003.

PENNA, F. de A. A escola sem partido como chave de leitura do fenômeno educacional. In: FRIGOTTO, G. (Org.). Escola "Sem" Partido: Esfinge que ameaça a educação e a sociedade brasileira. Rio de Janeiro: UERJ; LPP, 2017. P.35-48.

QUIJANO, A. Colonialidade do poder, eurocentrismo e América Latina. In: LANDER, E. A colonialidade do saber: eurocentrismo e perspectiva latinoamericanas. Buenos Aires: CLACSO, 2005.

SANTOS, B. de S. A gramática do tempo: para uma nova política. São Paulo: Cortez, 2010. 
SANTOS, M. As cidadanias mutiladas. In: Governo do Estado de São Paulo; Secretaria da Justiça e da Defesa da Cidadania, Secretaria de Estado e Cultura. O preconceito. São Paulo: UMESP, 1997.

SCHWARCZ, L. M. O espetáculo das raças: cientistas, instituições e questão racial no Brasil - 1970-1930. São Paulo: Companhia das Letras, 1993.

SENNETT, R. O artífice. Rio de Janeiro: Record, 2009.

SILVA, T. T. (Org.). Identidade e Diferença: a perspectiva dos estudos culturais. Petrópolis, Rio de Janeiro, 2014.

SILVA, T. T. Documentos de Identidade: uma introdução às teorias do currículo. Belo Horizonte: Autêntica, 2010.

SKIDMORE, T. E. Preto no branco: raça e nacionalidade no pensamento brasileiro - 1870-1930. São Paulo: Companhia das letras, 2012.

SOUZA, C. Políticas públicas: uma revisão da literatura. Sociologias, Porto Alegre, ano8, n.16, jul/dez, 2006. P.20-45.

VAN DIJK, T. A. A ideologia. Disponível em: www.discursos.org. Acesso em: 01 de maio de 2016.

Recebido em: 22 de dezembro de 2018 Aprovado em: 29 de agosto de 2019 